\title{
LA ULTIMA INVASION ARMADA. LOS CONTINGENTES MILITARES ESPAÑOLES A LAS GUERRAS DE CUBA, SIGLO XIX
}

\author{
POR \\ CESAR R. YAÑEZ GALLARDO \\ Facultad de Ciencias Económicas, \\ Universidad de Barcelona
}

\section{INTRODUCCIÓN}

Durante la segunda mitad del siglo XIX se produjeron las mayores migraciones transcontinentales de la historia contemporánea. Europa, principalmente, aportó importantes contingentes de población a los países que se formaban en zonas ultramarinas con escasa densidad demográfica. El recuento estadístico publicado en 1929 por Ferenczi y Wilcox (1), nos entrega una cifra en torno a los 45 millones de europeos que emigraron a Ultramar entre 1815 y 1924. España se integró a estos grandes movimientos migratorios junto con los países de la Europa meridional, engrosando la emigración masiva desde la segunda mitad del siglo XIX en un volumen total aproximado de 4 millones y medio de pasajeros entre 1860 y 1930 (2); quedando aún por precisar la cuantía de la emigración ultramarina española en el período anterior a 1860. En este sentido existen indicios en Cataluña, País Vasco, Galicia, Asturias o Canarias, que permiten pensar que esa emigración temprana, fue importante en determinadas regiones y se dirigió a Cuba en forma preferencial, sin llegar a niveles de emigración en masa.

Siglas UTILIZADAS:

AHCT: Archivo Histórico de la Compañía Trasatlántica.

AMB: Archivo Marítimo, Barcelona.

IGE: Instituto Geográfico y Estadístico.

MMB: Museo Marítimo, Barcelona. 1929.

(1) I. Ferenczi y W. F. Wilcox (ed.), International Migrations, Nueva York,

(2) Nicolás SÁnchez-Albornoz (ed.), Españoles hacia América. Emigración én masa 1880-1930, Madrid, 1988. 
Las explicaciones que se han formulado para estas migraciones han sido fundamentalmente de orden económico y demográfico: formación de un mercado mundial de mano de obra, desplazamiento de factores económicos que relacionan movimientos de capital, mercancías y trabajadores en una única corriente entre Europa y América, apoyada por innovaciones tecnológicas que redujeron las jornadas de navegación transatlántica, y en consecuencia los precios de los pasajes de los emigrantes. Esto desde la perspectiva económica; desde el punto de vista demográfico, se pone el acento en el crecimiento de la población europea, con sus efectos sobre la densidad demográfica, y la dificultad de la agricultura y la industria para dar ocupación a las nuevas e incrementadas generaciones de europeos, lo que hubiera generado un excedente de población que tuvo salida a través de la emigración. A estas explicaciones habría que agregar las causas políticas y religiosas que provocaron la expatriación de un número importante de europeos hacia Ultramar, y los factores sociales que favorecieron el incremento de las masas de emigrantes: particularmente lo que se ha estudiado como los efectos de las cadenas migratorias, intentando ir más allá del análisis de factores de expulsión, atracción y dificultades intermedias, que tan bien se acomoda al análisis económico.

Este tipo de teorías han servido para explicar las salidas de trabajadores que podían decidir voluntariamente, dentro de lo que cabe de voluntario después de la presión de los factores de expulsión, el momento y el destino de sus desplazamientos, así como la ocupación o profesión que ejercerían en los lugares de destino. En el caso de España, este tipo de emigración fue acompañada a lo largo del siglo XIX, por un importante volumen de "emigración oficial» constituida en su mayor parte por militares - jefes y oficiales acompañados de sus familias, pero sobre todo soldados sorteados en quintas o de reemplazo-, funcionarios civiles del Estado, y en menor medida por misioneros, miembros de órdenes religiosas, penados y deportados políticos. España no fue un caso único en este sentido, cabe destacar la experiencia británica, que con sus colonias penales inició el poblamiento europeo en Australia, y los contingentes militares enviados a la India o Suráfrica.

\section{APROXIMACIÓN CUANTITATIVA A LAS MIGRACIONES ESPAÑOLAS A CUBA}

El aspecto cuantitativo de la salida de militares desde España 
a sus colonias, requiere detenerse brevemente en el problema que representan las fuentes. Contamos con la publicación del Instituto Geográfico y Estadístico (3), que nos entrega una cifra total anual de los militares y funcionarios civiles del Estado que entraron y salieron por los puertos españoles a partir de 1882 . Esta fuente, considerada la estadística oficial, contiene varios defectos a señalar, tanto porque no refleja el número real de los embarques de militares y funcionarios, como porque no recoge en forma desagregada todas las categorías de la emigración oficial. Detectamos las carencias en los datos del Instituto Geográfico y Estadístico en el momento que hemos podido contrastarlos con otras fuentes, en este caso, con los datos que se conservan en el archivo de la Compañía Trasatlántica, la que desde 1861, primero con el nombre de Antonio López y Cía., disfrutó del contrato exclusivo para el transporte de los pasajeros del gobierno español. Con la documentación de la Trasatlántica se ha podido conocer las diferentes categorías de militares que se embarcaron a América, clasificados según eran jefes u oficiales, o soldados, diferenciación que la empresa debía distinguir por las diferentes tarifas que cobraba al gobierno para el transporte de los distintos estamentos militares, que según su rango ocupaban diferentes categorías de cámara. Por esta documentación, también sabemos que el Estado sufragaba los gastos de transporte de los familiares de jefes y oficiales que eran desplazados a territorios coloniales, así como de los hombres y mujeres dedicados al culto, y miembros de órdenes religiosas. Por último un grupo más difícil de cuantificar, pero que del mismo modo eran transportados por la Trasatlántica a cargo de su contrato con el Estado, eran los penados y deportados conducidos a los presidios de las colonias para cumplir condena, o los sujetos que eran llevados a la Península para ser juzgados.

En esta oportunidad nos ocuparemos de los grupos más importantes de la emigración oficial dependiente directamente del Estado: militares, funcionarios y sus familias, quedando por cuantificar los grupos minoritarios (curas, monjes, deportados y condenados).

Mediante la comparación de ambas fuentes se intentará una

(3) Instituto Geográfico Estadístico, Estadística de la emigración e inmigración de España 1882-1890, 1891-189.5, 1896-1900, 1901... 1911, Madrid 1891-1912; Estadística de pasajeros por mar 1919, Madrid, 1923; Jefatura Superior de Estadística, Estadistica de pasajeros por mar 1920-1921-1922, Madrid 1924; Servicio General de Estadística, Estadistica del movimiento de buques y pasajeros por mar con el exterior 1923, 1924, 192.5, Madrid; Instituto Geográfico Catastral y de Estadística, Estadística del movimiento de buques y pasajeros por mar 1926-1931, Madrid. 
primera aproximación al problema de la cuantificación de la emigración oficial española. En primer lugar, señalar las diferencias detectadas entre las estadísticas del Instituto Geográfico y Estadístico, y las cifras de la Trasatlántica: si comparamos los transportes de militares a Cuba (véase cuadro 1), obervamos que entre 1882 y 1905 hay una diferencia de 76.510 militares que no recogen las estadísticas del organismo estatal, y que sí están registradas en las cuentas de la Trasatlántica. En este punto se podrían cuestionar los datos de la compañia de Antonio López, la que podría haber intentado aumentar las cantidades de soldados transportados para incrementar el cobro del transporte oficial.

CUAdRo 1. MILITARES A CUBA ENTRE 1868 y 1905

\begin{tabular}{rrrrrr}
\hline Año & $\begin{array}{c}\text { Compañia } \\
\text { Trasat. }\end{array}$ & $\begin{array}{c}\text { Inst. Geog. } \\
\text { y Estadís. }\end{array}$ & Año & $\begin{array}{c}\text { Compañía } \\
\text { Trasatl. }\end{array}$ & $\begin{array}{c}\text { Inst. Geog. } \\
\text { y Estadis. }\end{array}$ \\
\hline 1868 & 7.044 & - & 1887 & 3.536 & 5.768 \\
1869 & 26.200 & - & 1888 & 5.868 & 751 \\
1870 & 14.131 & - & 1889 & 3.226 & 932 \\
1871 & 17.819 & - & 1890 & 3.859 & 815 \\
1872 & 8.613 & - & 1891 & 8.779 & 2.108 \\
1873 & 11.995 & - & 1892 & 4.081 & 1.504 \\
1874 & 12.163 & - & 1893 & 5.135 & 1.031 \\
1875 & 19.499 & - & 1894 & 5.358 & 1.339 \\
1876 & 33.688 & - & 1895 & 103.761 & 67.354 \\
1877 & 17.818 & - & 1896 & 83.857 & 83.727 \\
1878 & 9.286 & - & 1897 & 15.316 & 13.643 \\
1879 & 26.323 & - & 1898 & 16.924 & 15.797 \\
1880 & 4.018 & - & 1899 & 427 & 227 \\
1881 & 5.982 & - & 1900 & 100 & 24 \\
1882 & 12.595 & 9.197 & 1901 & 53 & 38 \\
1883 & 8.115 & 5.293 & 1902 & 4 & 5 \\
1884 & 4.836 & 3.713 & 1903 & 3 & 17 \\
1885 & 2.892 & 250 & 1904 & 6 & 19 \\
1886 & 8.251 & 6.943 & 1905 & - & 31 \\
\hline
\end{tabular}

Fuentes: AHCT, AMB, IGE y Estadística de la Emigración e inmigración de España, 1882-1905 (Madrid 1891/1912).

Sin embargo parece más posible que al Instituto Geográfico se le escaparan algunas salidas del recuento, o que los gobiernos de la época intentaran minimizar los verdaderos envíos de tropas a las colonias ante la opinión del país, para evitar la reacción contra las levas y quintas, que contaban con la repulsa de los sectores populares y la oposición de los grupos políticos más radicales. Por otro lado, las cantidades que muestran los datos de la Trasatlántica se ven contrastados con otras fuentes, así por ejemplo entre 1895 y 1898 las salidas de militares registradas por el 
Instituto Geográfico hacia Cuba nos reflejan 180.512 individuos, en cambio los aproximadamente 200.000 militares que compusieron las 15 expediciones documentadas hacia Cuba (en total 131 vapores), coinciden con la cifra de militares llevados de la Península a La Habana por la Trasatlántica en esos mismos años, a los que sumados los embarcados desde Canarias eleva la cantidad a 219.858 militares transportados desde España a Cuba en los años de la Guerra de Independencia.

En segundo lugar, interesa hacer una valoración de la «emigración oficial» sobre el conjunto de la emigración ultramarina española. Para ello haremos una breve sinopsis de lo ocurrido en el siglo XIX.

La década de 1830, con especial atención al período en que el general Miguel Tacón ejerció la autoridad española en la Isla, representan años de cambio en la política colonial española en Cuba, el objetivo era provocar una "españolización" de sus posesiones americanas, tarea que fue finalizada en el período de la gobernación de Leopoldo O'Donnell (4). El temor a que se provocara un movimiento independentista que pusiera fin a la presencia colonial española en las Antillas, favoreció el cambio en la composición, volumen, y función del contingente militar español en sus últimas colonias americanas. Si durante el siglo XVIII y hasta el fin de las guerras de independencia americanas, Cuba y especialmente La Habana, había sido un punto de tránsito, especie de escala técnica obligada para el abastecimiento y aclimatación de los militares que eran enviados a los territorios coloniales, a partir de 1830 aproximadamente, se incrementó la presencia militar permanente en la Isla. Se trataba de un contingente entre 30 ó 50 mil hombres que, aunque participaron en las aventuras expansionistas de México y Santo Domingo, tenían como última finalidad garantizar la sujeción colonial de la misma isla de Cuba. Ya no se trata de unas fuerzas en tránsito hacia otras posesiones, sino de una presencia estable de militares, que a pesar de ser relevados períodicamente, tuvieron el carácter de fuerza militar permanente.

Pero, sin duda, lo que va a tener mayor influencia sobre lo que hemos llamado la "emigración oficial», será el cambio en la composición de los efectivos militares en América, sustituyendo

(4) Manuel Moreno Fraginal.s, "Inmigración, quintas y guerras coloniales. El caso cubano: 1834-1878", en III Jornades Catalano-Americanes, Barcelona, 1990, págs. 23-37. 
los batallones de «pardos» y «mulatos» por soldados y oficiales enviados desde la Península:

El celo infatigable de un ilustre general a quien hemos aludido ya [Tacón], introdujo en el ejército de la Isla la subordinación y el órden de que anteriormente carecía. Sin disciplina no hay fuerza, y sin fuerza las leyes no tienen apoyo, ni la autoridad prestigio. La conveniencia pública es de por sí solo un lazo muy débil a la consideración del díscolo, del turbulento, del interesado en trastornos. Estas máximas, acomodadas a todas las naciones desde que todas mantienen ejércitos armados en tiempos de paz, son doblemente aplicables a la colonia donde sobre las causas comunes de temor por el órden público se cuenta el deseo inquieto de romper los vínculos con la metrópoli. Este deseo alaga especialmente a los hijos del país y a las razas africanas: a los primeros por las ansias de mandar; a las segundas por la ocasión de vengarse. La Isla, pues, necesita de un ejército subordinado y compuesto todo de españoles sin tacha en su conducta. Los naturales del país no deben tener entrada en sus filas, porque sería imprudente confiar la subordinación a los que tienden a destruirla. Las milicias de indígenas a quienes se confió en América la conservación de la tranquilidad pública convirtieron en el primer lance sus armas contra los derechos de la metrópoli. Otro tanto sucedería en la isla de Cuba si incurriesemos en el desacierto de admitir en su guarnición a los hijos del país.

No es esto privar a los cubanos de la goloriosa carrera de las armas. Abierta deben tener siempre la entrada en los ejércitos de la Península, donde pueden hacer útiles servicios, y obtener grados y honores que satisfagan a la más noble ambición. Combinando, pues, los intereses de aquellos naturales con los derechos de la metrópoli, sería conveniente licenciar los regimientos fijos americanos, y permitir a los oficiales nacidos en la isla la continuación de su carrera en la Península.

Cuando el soldado permanece mucho tiempo en una guarnición contrae relaciones que le desvirtúan. El militar debe ser extraño a las influencias locales: su deber es la ciega obediencia, que se sostiene mal cuando es necesario obrar contra las propias inclinaciones, nacidas de hábitos envejecidos y a su vez de intereses positivos. De aquí el preciso relevo que de tiempo en tiempo conviene hacer a las guarniciones de la Isla; relevo cuanto más indispensable cuanto que tratándose de evitar que el soldado pierda su energía, ningún país of rece este inconveniente en tanto grado como la isla de Cuba, donde todo trabajo 
halla un premio extraordinario, y donde todo convida a procurar fortuna (5).

Desde la cuarta década del siglo pasado, el envío de tropas a Cuba aumentó de forma considerable. Mayoritariamente provenientes de quintas (6) entre 1868 y 1905 según los datos de Trasatlántica van a representar un total de 503.349 individuos entre oficiales y tropa, alcanzando su mayor intensidad en los años de guerras coloniales, más de 180.000 entre 1868 y 1878 , y más de 220.000 entre 1895 y 1898. Sobre la Guerra de los Diez Años, Jover Zamora ha escrito lo siguiente para evaluar el costo humano que representó para España:

En conjunto, las fuerzas recibidas desde la Península durante los diez años de duración de la guerra alcanzará la cifra de 181.040 hombres; de ellos morirán 96.025 , el $91 \%$ de los cuales por enfermedades y solo el $8,3 \%$ por acción de guerra, más de 25.000 serán devueltos a la Península, por enfermos o inútiles, muriendo aproximadamente el $12 \%$ de ellos, bien durante la travesía o poco después de su desembarco (7).

En el cuadro 2 podemos comparar los militares que fueron enviados a Cuba desde 1868 a 1899, período que cubre las dos guerras de independencia cubanas y los años intermedios de paz, con los emigrantes civiles españoles que fueron a América en su conjunto, y a Cuba en particular. En esta fase, más de medio millón de españoles fueron a Cuba para defender el orden colonial, en términos cuantitativos se trató de uno de los ejércitos coloniales más importantes desplazados fuera de Europa hasta la época. - solamente Gran Bretaña lo superó con los 450.000 hombres enviados a Suráfrica entre 1899 y 1902-. Con respecto a los emigrantes españoles que se dirigieron de forma definitiva o transitoria a Cuba, los militares los superaron en número, aunque habría que decir que la emigración de trabajadores y viajeros en general fue un fenómeno mucho más regular en el tiempo, con

(5) Texto anónimo, Estado actual de la isla de Cuba y medios que deben adoptarse para fomentar su prosperidad con utilidad de la madre patria, Madrid, Imprenta de la Compañía general de Impresores y Libreros, 1838, págs. 16-17 (ejemplar de la Biblioteca Carandell del Departament d'Economia i Historia Economica de la Universitat Autónoma de Barcelona).

(6) En el censo de la isla de Cuba de 1841 se contaron 38.000 transeuntes, y 30.000 aproximadamente en el de 1846.

(7) Nuria Salas, "Servicio Militar y sociedad en la España del siglo XIX", en Sobre esclavos, reclutas y mercaderes de quintas, Barcelona, 1974, págs. 209-246. 
unas oscilaciones marcadas por el comportamiento de la economía azucarera dominante en Cuba, mientras que los contingentes de militares se concentran en los años de guerras coloniales, $1868-1878$ y $1895-1898$.

CUADRo 2. EMIGRACION ESPAÑOLA A AMERICA, A CUBA Y MILITARES A CUBA, 1860-1899

\begin{tabular}{|c|c|c|c|c|c|}
\hline Año & $\begin{array}{c}\text { Salidas } \\
\text { a América } \\
1\end{array}$ & $\begin{array}{c}\text { Salidas a } \\
\text { Cuba } \\
2\end{array}$ & $\begin{array}{c}\text { Militares a } \\
\text { Cuba. } \\
3\end{array}$ & $\begin{array}{c}1+3 \\
4\end{array}$ & $\begin{array}{c}2+3 \\
5\end{array}$ \\
\hline 1860 & 12.845 & 11.915 & - & - & - \\
\hline 1861 & 9.674 & 8.888 & - & - & - \\
\hline 1862 & 10.961 & 8.861 & - & - & - \\
\hline 1863 & 10.923 & 8.685 & - & - & - \\
\hline 1864 & 13.173 & 10.237 & - & - & - \\
\hline 1865 & 14.027 & 10.666 & - & - & - \\
\hline 1866 & 13.861 & 10.437 & - & - & - \\
\hline 1867 & 16.138 & 11.415 & - & - & - \\
\hline 1868 & 20.042 & 14.035 & 7.044 & 27.086 & 23.034 \\
\hline 1869 & 20.056 & 14.005 & 26.200 & 46.256 & 42.180 \\
\hline 1870 & 19.062 & 13.698 & 14.131 & 33.193 & 29.767 \\
\hline 1871 & 16.661 & 11.880 & 17.819 & 34.480 & 31.416 \\
\hline 1872 & 22.392 & 15.045 & 8.613 & 31.005 & 25.867 \\
\hline 1873 & 25.776 & 14.475 & 11.995 & 37.771 & 28.586 \\
\hline 1874 & 25.464 & 14.978 & 12.163 & 37.627 & 29.355 \\
\hline 1875 & 20.865 & 14.616 & 19.499 & 40.364 & 36.289 \\
\hline 1876 & 18.218 & 12.200 & 33.688 & 51.906 & 47.280 \\
\hline 1877 & 14.287 & 10.060 & 17.818 & 32.105 & 29.382 \\
\hline 1878 & 19.629 & 10.783 & 9.286 & 28.915 & 21.680 \\
\hline 1879 & 23.392 & 15.109 & 26.323 & 49.715 & 43.536 \\
\hline 1880 & 19.747 & 12.055 & 4.018 & 23.765 & 17.789 \\
\hline 1881 & 21.539 & 11.319 & 5.982 & 27.521 & 18.913 \\
\hline 1882 & 26.412 & 13.830 & 12.595 & 39.007 & 26.425 \\
\hline 1883 & 29.099 & 16.079 & 8.115 & 37.214 & 24.194 \\
\hline 1884 & 32.863 & 10.038 & 4.836 & 37.699 & 14.874 \\
\hline 1885 & 19.147 & 7.939 & 2.892 & 22.039 & 10.831 \\
\hline 1886 & 30.742 & 14.363 & 8.251 & 38.993 & 22.614 \\
\hline 1887 & 40.193 & 16.654 & 3.536 & 43.729 & 20.190 \\
\hline 1888 & 56.264 & 18.344 & 5.868 & 62.132 & 24.212 \\
\hline 1889 & 112.352 & 20.268 & 3.226 & 115.578 & 23.494 \\
\hline 1890 & 53.598 & 20.239 & 3.859 & 57.457 & 24.098 \\
\hline 1891 & 53.847 & 20.574 & 8.779 & 62.626 & 29.353 \\
\hline 1892 & 49.647 & 28.558 & 4.081 & 53.728 & 32.639 \\
\hline 1893 & 80.126 & 26.995 & 5.135 & 85.261 & 32.130 \\
\hline 1894 & 47.685 & 27.636 & 5.358 & 53.043 & 32.994 \\
\hline 1895 & 42.923 & 9.160 & 103.761 & 146.693 & 112.921 \\
\hline 1896 & 54.085 & 6.526 & 83.857 & 137.942 & 90.383 \\
\hline 1897 & 54.946 & 10.504 & 15.316 & 70.262 & 25.820 \\
\hline 1898 & 37.786 & 5.709 & 16.924 & 54.710 & 22.633 \\
\hline 1899 & 46.231 & 14.976 & 427 & 46.658 & 15.403 \\
\hline $1868-99$ & 1.155 .885 & 449.287 & 511.395 & 1.667 .280 & 1.010 .682 \\
\hline
\end{tabular}

Fuente: AHCT. 
Comparando las salidas de españoles a todos los destinos americanos con los militares a Cuba, reconocemos que estos últimos representan la mitad de los emigrantes españoles del período 1860-1899, lo que en conjunto hace subir las salidas de españoles a ultramar a más de 1.660.000. Inicialmente, hasta mediados de la década de los ochenta del siglo pasado, la inmensa mayoría de las salidas van a Cuba, pero a partir de 1887 se incrementan las migraciones hacia Argentina y Brasil, por lo que se reduce el peso de los militares sobre el conjunto de la emigración española. La excepción son los años de la guerra de 18951898, años en los que el número de militares supera con mucho el de emigrantes civiles a todos los países americanos.

En cuanto a la diferencia entre salidas y entradas, solamente podemos establecer la comparación para el período de 1882 a 1899. Las cifras del Instituto Geográfico y Estadístico reflejan que al menos el $80 \%$ de los emigrantes españoles a Cuba volvieron a su país, y que el $85 \%$ de los militares fueron repatriados, generalmente después de un período relativamente corto en la Isla. Es posible que aproximadamente 35.000 militares españoles no volvieran de Cuba en las dos últimas décadas del siglo pasado, pero no podemos saber todavía cuántos de ellos fueron bajas $\mathrm{y}$ cuántos pudieron haber decidido permanecer en la Gran Antilla como residentes. Solamente podemos confirmar las apreciaciones de Jover Zamora, antes citadas, en el sentido que una parte importante de las bajas eran el resultado de las condiciones insalubres en que vivían y hacían la travesía atlántica los soldados.

Intentando una evaluación del costo demográfico de la emigración oficial española a América, se confirma lo expuesto por Ricardo Robledo, en el sentido que las movilizaciones de finales del siglo XIX forzaron la salida del territorio español de aproximadamente el $20 \%$ de la población masculina entre 21 y 30 años de edad (8); y que la emigración oficial neta entre 1887 y 1900 en dirección a América - según cifras de la Cía. Trasatlánticaunos 25.500 individuos, representaron más del 30\% del incremento de ese grupo de edad (entre 21 a 30 años), entre los dos años censales citados.

La mayor parte de los militares movilizados hacia las colonias, reclutados mediante un sistema que permitía la sustitución y la remisión por dinero, llevó a los hijos de las familias pobres al

(8) José María Jover Zamora, "La época de la Restauración panorama político-social, 1875-1902", en Historia de España dirigida por Manuel TUNón DE LARA, vol. VIII, pág. 314. 
frente para "pagar su impuesto de sangre» a la patria (9). Los efectos sociales de este sacrificio impuesto a las clases populares, que, desde un punto de vista, podría ser identificado con la disminución de la presión demográfica, o la reducción del desempleo, que, a su vez, podría haber representado una válvula de escape para los conflictos en la Península (10), tuvo su contrapartida en el incremento de la reacción contraria al servicio militar obligatorio; rechazo que se difundió con mayor intensidad después que los 210.000 repatriados de la guerra de Cuba pudieron difundir en su radio de acción inmediato y personal las malas condiciones en que se servía en el ejército en los territorios de Ultramar.

En Cuba, los efectos de la invasión de este medio millón de militares no ha sido evaluado, y aquí sólo podemos apuntar algunas conjeturas generales. En primer lugar, dejando a un lado los efectos directos de las guerras, hay que considerar que las colonias debían financiar los costes de su "defensa", lo que representaba que la Caja de la Hacienda de La Habana debía costear el transporte de militares tanto a Cuba como a Puerto Rico. Y en segundo término, debía hacerse cargo de la manutención de la tropa, el mantenimiento de la infraestructura y logística bélica, que estaba allí para ser usada en su contra. La economía cubana, deteriorada por la constante caída de los precios del azúcar a lo largo de la segunda mitad del siglo XIX, producto de la competencia de la fabricación de azúcar de remolacha, y la carga que significó la aventura española en México y Santo Domingo, debía soportar en su suelo un contingente militar que durante la primera guerra, la de los Diez Años, fue de 70.000 hombres como promedio, 30.000 en los años de paz y más de 100.000 en los años de la Guerra de Independencia, 1895-1898.

(9) Ricardo RoBledo, "Crisis agraria y éxodo rural: Emigración a Ultramar 1882-1920", comunicación al Congreso Internacional sobre la Crisis de la Agricultura Europea a fines del siglo XIX, Gerona (Barcelona) 1988, págs. 212-244. Vid. (6).

(10) César YÁÑEZ, "Emigración, conflicto social y política migratoria en la España de la Restauración. Una aproximación al tema de la emigración exterior y el control social", en Roberto Bergalli y E. M. MARY, (coord.), Historia e ideología del control social (España y Argentina siglos XIX y XX). Barcelona 1989, págs. 95-125. Para los datos del total de la emigración a Ámérica y Cuba véase César YÁÑEz "Reconstrucción de las series anuales de emigración española a América (1860-1930)" II Congreso Hispano-Luso de Historia de la Poblacion (Actas, en prensa). 
2. EL MONOPOLIO DE LOS TRANSPORTES OFICIALES. LAS RELACIONES DE LA TRASATLÁNTICA CON EL ESTADO ESPAÑOL

El primer contrato de Antonio López para el transporte de la correspondencia a Ultramar, le fue adjudicado el 11 de septiembre de 1861 por un valor de 29.500 pesos por viaje redondo que incluía el circuito entre la Península, la Isla de Cuba, Puerto Rico y Santo Domingo, que se debía servir con 8 buques de vapor.

CUADRo 3. PRECIOS DE LOS PASAJES OFICIALES EN 1862 (Ps. fs.)

\begin{tabular}{lccc}
\hline & Cuba & Puerto Rico & Santo Domingo \\
\hline Oficiales & 71,42 & 68,00 & 69,30 \\
Sargentos & 25,01 & 22,66 & 24,60 \\
Cabos y soldados & 20,00 & 17,00 & 18,70 \\
\hline
\end{tabular}

Fuente: Colección de Reales órdenes, y decretos de la Cía. Trasatlántica, R. O. 10 de febrero de 1862.

Este contrato era de un año de duración y le fue renovado al año siguiente por un período de 5 años. Las condiciones generales no variaron en lo sustancial, pero la renovada presencia colonial española en Santo Domingo, puso en el centro de las relaciones de Antonio López con el gobierno la cuestión del transporte extraordinario de tropas a las colonias. En el artículo 31 del Pliego de Condiciones para el transporte de correspondencia entre la Península y las Antillas, firmado en 1862, la empresa de A. López se obligaba a transportar en los "vapores correo" a los soldados y marineros que el gobierno destine a Cuba y Puerto Rico, "con arreglo a las tarifas de la Real órden circular de 7 de agosto de 1842, partiendo de la base de que en vez de los treinta y cinco y treinta siete pesos que ésta señala respectivamente para cada soldado, solo se pagarán veinte y diez y siete pesos y que todos los demás precios se arreglabán proporcionalmente a estas rebajas" (11). Con respecto a los familiares de los militares se establecía que el Estado abonaría a la empresa por las mujeres de los oficiales la mitad del pasaje de éstos, y por los hijos y madre viuda cuya subsistencia dependa de ellos, ración y media

(11) Colección de Reales Ordenes del Archivo Histórico de la Compañía Trasatlántica, Real Orden 11 y 12 de 1862, Sección 3, Carpeta 1, Legajo 1. 
de la armada diaria valorada a 4 reales de plata, siendo de cuenta de los interesados el resto hasta completar el precio del pasaje.

Los precios que pagaba el gobierno por los militares y miembros de la armada que se dirigían a las Antillas en 1862, se vieron sensiblemente reducidos con respecto a las tarifas de 20 años antes (entre un 30\% o un 50\% más baratos), reflejo en última instancia de la evolución internacional de los precios de pasajes a Ultramar desde la generalización del uso del vapor. El pago por estos transportes se hacía mensualmente a cargo de las cajas de la isla de Cuba, siguiendo la normativa de 1842, por la cual las colonias debían financiar su defensa. Pero la Compañía Trasatlántica hizo todo lo posible para que los transportes oficiales a las Antillas fueran a cargo de la Hacienda Pública y pagados por adelantado, ya que temían las dificultades para cobrar directamente de las cajas coloniales, sobre todo por los retrasos con que habitualmente cancelaba el gobierno. En este sentido, en junio de 1862, el Ministro de la Guerra y Ultramar confirmó que el gasto en concepto de transportes del ejército establecido en las colonias debía ser sufragado por las cajas de Cuba o Puerto Rico de acuerdo a lo dispuesto en el artículo 31 y 46 del pliego de Condiciones para el servicio de vapores correo:

que con el fin de evitar nuevas quejas por parte de la empresa se prevenga a V. E. y al Superintendente de Puerto Rico, dispongan lo conveniente para que el importe de los pasajes de las clases militares que verifiquen con vapores correo los abonen sin demora alguna después de corridos los trámites de justificación, por ser este un servicio preferente del Estado: y que en atención a que los citados vapores no tocan en la capital de la isla de Santo Domingo y a que en Samaná no existen fondos para responder al pago de los pasajes de los individuos destinados a dicha Isla, tenga éste lugar en las cajas de la isla de Cuba o de Puerto Rico según mejor convenga a la empresa, advirtiendo que en caso de ser por esta última Isla, se pasen los cargos a la de Cuba, a quién hoy está afecto el pago de las obligaciones de Santo Domingo... (12).

Las condiciones generales para el negocio del transporte oficial de tropas a Ultramar habían quedado establecidos en el año 1862. Un año después, a propósito de la ocupación española en

(12) Ibidem, Real Orden 33 de 1862, Sección 3, Carpeta 1, legajo 1. AMMB. 
Santo Domingo, Antonio López, recibió el encargo de transportar 1.000 hombres al Caribe, a los precios establecidos en el artículo 31 del pliego de condiciones, renunciando al cobro inmediato de las cajas de Ultramar; a cambio obtuvo una indemnización en caso de alterarse determinadas condiciones del contrato respecto a escalas y estadías (13). Era la primera oportunidad para comprobar el funcionamiento de la contrata de transportes extraordinarios de militares, y saber hasta que punto el gobierno estaba dispuesto a ejercer su poder fiscalizador.

En 1868, el gobierno convocó nueva subasta a la que concurrieron A. López y José Ferrer y Vidal, este último ofrecía cumplir en su totalidad el pliego de condiciones de fecha 21 de enero de 1868, por un precio de 69.999 escudos por viaje redondo; mientras López estaba dispuesto a bajar esa oferta hasta 67.000 escudos con los ocho vapores que tenía en funcionamiento (y con los que provisionalmente desempeñaba el servicio), y por 59.000 escudos si se volvía a las condiciones del 19 de junio de 1861. Pero el gobierno desestimó estas ofertas, «por excesivas en sus pretensiones", y devolvió a los proponentes las garantías que habían depositado en la caja general del ramo ( 8 millones de rs. vn.). Sin embargo, dos días después, el 16 de abril de 1868, el Ministerio de Ultramar concedía el servicio de conducción de la correspondencia por medio de vapores desde la Península a Cuba y Puerto Rico a la Antonio López y Cía. de Alicante por 60.500 escudos, cantidad que rebajaba en un $10 \%$ aproximadamente la propuesta inicial de López, con el beneficio adicional de que nueva contrata tenía una duración de 10 años.

Si bien las aspiraciones de la compañía de A. López se habían tenido que reducir por la competencia de la subasta, los ingresos que dejó de percibir por este concepto se vieron rápidamente compensados por el estallido de la Primera Guerra de Cuba. El transporte de tropas y material de guerra, a partir de este momento, se convertirá en el elemento central del rodaje económico de la empresa, sirviendo además para que ante la opinión pública, la compañía concesionaria y el mismo Antonio López, se rodearan de una aureola de patriotismo que acompañará permanentemente sus actividades (14). Si hasta ese momento la protección del Estado había resultado imprescindible para poder superar, o al

(13) Ibidem, Real Orden 61 de 1862, Sección 3, Carpeta 1, legajo 2. AMMB.

(14) Elena Hernandez Sandoica, Pensamiento burgués y problemas coloniales en la España de la Restauración, Tesis de Doctorado leída en la Universidad Complutense de Madrid el año 1982, Madrid, 1982, págs. 874-876. 
menos neutralizar, la competencia internacional en el tráfico atlántico, e incluso así existían graves dificultades, la coyuntura de las guerras coloniales vino a consolidar la relación entre el Estado y la Compañía de A. López, en un marco de protección de actividades consideradas estratégicas. El fin del conflicto cubano redujo significativamente el transporte de militares, y probablemente se redujeron en la misma proporción los ingresos de la compañía. Pero se había conseguido crear una situación ambigua en la que la naviera de Antonio López podía disfrutar no sólo de la subvención oficial, sino también de su complacencia respecto de las condiciones de cumplimiento del contrato, estado del material flotante, condiciones del pasaje de tercera clase y cumplimiento de los itinerarios. En esas condiciones, no hubo dificultad para renovar el contrato con el Estado a partir de marzo de 1878, ampliándolo por otros 10 años, comprometiéndose a ampliar su flota a 12 vapores y aceptando un mayor control sobre el cobro de los transportes oficiales. A cambio de este endurecimiento de las condiciones de la contrata, la compañía se aseguraba el pago de los deberes adeudados por los servicios extraordinarios que había prestado durante la década anterior, en especial la que se había acumulado en los años de las guerras en América, además de la prolongación de la subvención por una década más.

Por algún tiempo el asunto de los transportes oficiales estará relegado a un segundo plano, la reducción de los contingentes desplazados a las Antillas obligaba a buscar nuevas fuentes de financiamiento y se entró en una dura competencia por el control del tráfico subvencionado a Filipinas. Pero el mayor esfuerzo se orientó hacia la reconversión de la Antonio López y Cía. en una sociedad anónima por acciones, que en 1881 tomará el nombre de Compañía Trasatlántica S. A., la cual recibió los bienes, equipo y el personal de su antecesora, y heredó la contrata que tenía con el Estado. En este contexto, ampliaba su capital poniendo en circulación acciones y bonos de deuda, que sirvieron para aumentar sus servicios hacia América, creándose nuevas rutas en dirección a México, Estados Unidos, Venezuela y el cono sur de América. La reducción de los ingresos que recibía por concepto de transporte de tropas, obligaba a la compañía a intentar un proceso de modernización que le permitiera ganar nuevos mercados, mejorar sus servicios y ampliar su of erta, de manera de poder desplazar a las compañías extranjeras que recalaban en los puertos españoles a recoger emigrantes y mercaderías.

A pesar de estos esfuerzos, la Trasatlántica aumentó el déficit 
que arrastraba la compañía antecesora. La alternativa más al alcance de la mano era intensificar la dependencia de los presupuestos oficiales y apoderarse de la mayor parte del tráfico oficial. En el contrato aprobado por el Consejo de Ministros el 17 de noviembre de 1886, y ratificado por la Trasatlántica el día 18 del mismo mes, se definían las condiciones de la subvención en los siguientes términos:

Artículo 1. El contratista que tome a su cargo este servicio se compromete a desempeñar los servicios de comunicaciones marítimas que se determinan en el artículo 2 , con buques de vapor que reunan las condiciones que más adelante se detallan; a conducir a bordo de los mismos, con destino a los puertos indicados en el dicho artículo 2, la correspondencia pública y de oficio, y el pasaje y carga oficial, y por último, a prestar con dichos buques los servicios auxiliares de guerra de que sean susceptibles, subordinándose en todo a las prescripciones de este pliego (15).

Se establecía que, por una duración de 20 años, la Compañía realizaría anualmente 36 viajes redondos entre Cádiz-Santander y las Antillas, pudiendo hacer escala en Las Palmas de Gran Canaria, debiendo extenderse todos a Nueva York y Veracruz, y uno al mes a La Guaira, Puerto Cabello, Sabanilla, Cartagena y Colón, estableciendo combinaciones a la costa del Pacífico y a Nueva Orleans. La segunda línea era la de Inglaterra-BarcelonaManila que debía realizar 13 viajes redondos; se establecían también 6 viajes del Mediterráneo y Cantábrico a Buenos Aires, Montevideo y Río de Janeiro; 4 a Fernando Poo y 24 viajes anuales que debían tocar en los puertos de Málaga, Ceuta, Algeciras, Tánger y Cádiz.

El sistema de subvenciones cambiaba sustancialmente en relación al empleado hasta ahora, asignándose una cantidad por millas de recorrido: 10,18 pesetas en la ruta de las Antillas, 7,15 en la de Filipinas, 0,73 en las combinaciones al interior de América, 5,93 en las rutas de navegación que iban a Buenos Aires, y la misma cantidad a Fernando Poo y Marruecos (16). Si comparamos las subvenciones de 1886 con las de las contratas anteriores, calculando que en el derrotero de las Antillas (que era el más

(15) Contrato celcbrado con la Compañia Trasatlántica aprobado por el Consejo de Ministro el 17 de noviembre de 1886, Diario de Sesiones de Cortes, Congreso, 4 de diciembre de 1886, tomo IV, apéndice 1 al 78, citado por Hernández Sandoica [14].

(16) Artículo 5 del contrato de 1886 entre la Compañía Trasatlántica y el gobierno. 
importante) se navegaban aproximadamente 10.000 millas en un viaje redondo, la subvención alcanzaría más o menos las 100.000 pesetas, que rebaja casi en un tercio las cantidades por viaje redondo de las anteriores contratas. Pero, el aumento en la cantidad de millas navegadas implícitas en la apertura de nuevas líneas y el aumento del número de viajes contratados, hacía que aumentara, en términos globales, el volúmen total de las subvenciones estatales a la empresa. Y todavía quedaba el apartado de los viajes de militares, funcionarios y carga oficial.

En cuanto a los transportes oficiales el artículo 53 del nuevo pliego de condiciones establecía lo siguiente: «El gobierno podrá disponer de la cuarta parte de las plazas destinadas a bordo de los buques de pasajeros, con el fin de transportar a todos los individuos activos y licenciados del ejército y la armada, y a los funcionarios de las demás carreras del estado que destine a las colonias o puertos del extranjero, o que regresen de unos $u$ otros, a los licenciados de establecimientos penales, y a los individuos que a ellos sean conducidos; a las Hermanas de la Caridad y a los misioneros que se dirijan de unos a otros puertos españoles; a los deportados, y a los pobres que se hallen bajo el amparo de la autoridad, y finalmente, a las mujeres, hijos y madres viudas de los jefes y oficiales del ejército y la armada, de los funcionarios públicos, y de los individuos de la Guardia Civil que se hallen en el mismo caso». A continuación el artículo establecía los precios de los transportes para todos los casos mencionados, que como regla general, debían ser inferiores a los de común aplicación: los de primera y segunda clase en un 30\%, los de tercera a Cuba en un 60\%, y en las otras líneas las rebajas debían ser del $35 \%$ para la tercera clase. Los trayectos servicios en combinación, debían tener un descuento en la tarifa oficial de un $20 \%$ en todas sus líneas. En estas tarifas quedaba incluido el pasaje y la manutención que la compañía debía proporcionar a los jefes y oficiales, y a la tropa siempre que el traslado fuera desde puertos de la Península al depósito de bandera de Ultramar, o viceversa.

El cumplimiento del pliego de condiciones obligaba al gobierno a transportar a todas las clases mencionadas en los buques de la empresa concesionaria, y ésta quedaba relevada de derechos de internación de nuevos buques, abanderamiento, matrícula, y carga de cada uno de estos vapores. Como contrapartida a estos privilegios, el gobierno se reservaba el derecho a nombrar al gerente y administrador de la sociedad anónima a propuesta de 
una terna confeccionada por la Junta de Accionistas, y obligaba que las acciones fueran nominales e intransferibles sin el conocimiento y razón del gobierno. La compañía se aseguraba unos ingresos estables para un lapso de 20 años, pero aumentaba en tal medida su dependencia de las subvenciones públicas, que perdía una buena dosis de autonomía empresarial, quedando sujeta al control del gobierno a través de la presencia de éste en la dirección de la Compañía.

Durante el período de aplicación del último contrato, 18871905, el ramo de los transportes oficiales llegó a ser el más importante para la Trasatlántica. Entre el 1 de julio de 1887 y el 31 de diciembre de 1905, la compañía transportó sin distinguir entre puntos de origen y de destino, un total de 43.905 jefes y oficiales y 587.821 soldados, además de 33.345 familiares de los primeros. Si agregamos los funcionarios del Estado, o sea 22.831 personas, resulta que la Trasatlántica transportó en el período señalado 687.902 personas en sus diferentes trayectos de ida y vuelta entre la Península y América, o entre puertos americanos, además de las 20.000 toneladas de materiales bélicos (véase cuadro 4).

CUADRO 4. CARGA Y PASAJE TRANSPORTADO POR LA TRASATLÁNTICA ENTRE 1887 Y 1905

\begin{tabular}{rrrrrrr}
\hline Año & $\begin{array}{c}\text { Caballos } \\
\text { y mulas }\end{array}$ & $\begin{array}{c}\text { Toneladas } \\
\text { Material }\end{array}$ & $\begin{array}{c}\text { Jefes y } \\
\text { Oficiales }\end{array}$ & Soldados & Familia & $\begin{array}{c}\text { Funcion. } \\
\text { Civiles }\end{array}$ \\
\hline 1887 & - & 73 & 683 & 6.835 & 903 & 348 \\
1888 & - & 483 & 1.295 & 11.179 & 2.065 & 835 \\
1889 & - & 342 & 1.053 & 9.402 & 1.784 & 1.593 \\
1890 & - & 491 & 966 & 12.098 & 1.341 & 1.507 \\
1891 & - & 257 & 1.262 & 18.791 & 1.328 & 982 \\
1892 & - & 297 & 1.293 & 11.277 & 1.679 & 1.031 \\
1893 & 1.051 & 343 & 1.789 & 23.117 & 1.963 & 11.118 \\
1894 & 196 & 506 & 1.797 & 14.669 & 3.069 & 1.145 \\
1895 & - & 2.066 & 8.396 & 102.321 & 2.627 & 1.462 \\
1896 & - & 3.442 & 4.828 & 118.607 & 2.299 & 2.060 \\
1897 & - & 2.178 & 3.709 & 54.083 & 1.998 & 2.406 \\
1898 & - & 7.968 & 10.248 & 143.719 & 6.403 & 2.694 \\
1899 & - & 1.488 & 5.555 & 54.430 & 4.931 & 4.367 \\
1900 & 80 & 63 & 627 & 4.885 & 646 & 596 \\
1901 & - & 44 & 166 & 918 & 183 & 182 \\
1902 & - & 5 & 56 & 462 & 46 & 128 \\
1903 & - & 5 & 114 & 308 & 36 & 162 \\
1904 & - & 1 & 34 & 591 & 25 & 106 \\
1905 & - & 1 & 43.905 & 587.825 & 33.345 & 22.831 \\
\hline
\end{tabular}

Fuente: AHCT. 
La composición de la emigración oficial española, de acuerdo a sus diversas categorías y según los puntos de destino y origen, queda expuesta en el Cuadro 5 . Los soldados representan más del $85 \%$ del total de la emigración oficial, y el conjunto de militares -incluidos jefes y oficiales-, son más del $90 \%$. Según

\section{CuAdRo 5. MIGRACIÓN OFICIAL (1-7-1887 - 31-12-1905), SEGUN DESTINO Y ORIGEN}

\begin{tabular}{|c|c|c|c|c|}
\hline & $\begin{array}{l}\text { Jefes y } \\
\text { Oficiales }\end{array}$ & Soldados & Familia & $\begin{array}{l}\text { Funcion. } \\
\text { Civiles }\end{array}$ \\
\hline $\begin{array}{l}\text { Península a Puerto Rico } \\
\text { Puerto Rico a Península }\end{array}$ & $\begin{array}{l}1.076 \\
1.156\end{array}$ & $\begin{array}{l}16.577 \\
14.065\end{array}$ & $\begin{array}{l}2.361 \\
2.497\end{array}$ & $\begin{array}{r}635 \\
1.009\end{array}$ \\
\hline Doninculo I Hohono & 12570 & 220550 & 5701 & 270 \\
\hline $\begin{array}{l}\text { Península a La Habana } \\
\text { La Habana a Península }\end{array}$ & $\begin{array}{l}12.570 \\
10.750\end{array}$ & $\begin{array}{l}230.550 \\
127.675\end{array}$ & $\begin{array}{r}5.791 \\
10.081\end{array}$ & $\begin{array}{l}4.370 \\
6.879\end{array}$ \\
\hline Península a isla de Cuba & 3.988 & 76.059 & 2.573 & 90 \\
\hline Isla de Cuba a Península & 189 & 8.258 & 8 & - \\
\hline $\begin{array}{c}\text { Montevideo y Buenos Aires } \\
\text { a La Habana }\end{array}$ & - & 2.017 & - & - \\
\hline Entre puertos de Cuba & 331 & 3.794 & 24 & 19 \\
\hline Puerto Rico a La Habana & 528 & 1.959 & 41 & $\begin{array}{r}109 \\
52\end{array}$ \\
\hline La Habana a Puerto Rico & & 401 & 9 & \\
\hline Península a Manila & 4.435 & 40.547 & 3.284 & 3.836 \\
\hline Manila a Peninsula & 6.402 & 38.135 & 6.571 & 4.726 \\
\hline Sabuanga a Manila & 470 & 656 & - & - \\
\hline Canarias a Manila & 13 & 530 & - & - \\
\hline Canarias a Península & 349 & 5.356 & 21 & 15 \\
\hline Península a Canarias & 139 & 4.056 & 37 & 99 \\
\hline Canarias a Fernando Poo & 10 & 17 & 11 & 19 \\
\hline Fernando Poo a Canarias & 2 & 6 & - & 34 \\
\hline Península a Fernando Poo & 275 & 2.348 & 29 & 557 \\
\hline Fernando Poo a Península & 289 & 2.437 & 7 & 381 \\
\hline Península a Melilla & 561 & 9.803 & - & - \\
\hline Melilla a Peninsula & 87 & 2.575 & 1 & - \\
\hline
\end{tabular}

Fuente: AHCT, MMB.

el destino, la mayoría se dirige a América, y los movimientos entre Cuba y la Península son los que acumulan la gran mayoría de estos desplazamientos. En términos generales, la emigración 
oficial española neta es de signo negativo, salen más individuos que los que retornan, lo que tiene que ver con el alto riesgo de mortandad del grupo de militares. Inversamente, una migración neta positiva para la Península se registra en los casos de familiares y funcionarios civiles, para los primeros hay que recordar que se trata de los familiares de los jefes y oficiales del ejército español destacado en las Antillas, y el mayor número de retornos tienen que ver con el nacimiento de hijos en las familias de estos militares, y probablemente también, los matrimonios entre oficiales jóvenes e hijas de las familias criollas o españolas afincadas en esos territorios. El caso de los empleados del Estado, nos llevaría a pensar en funcionarios del gobierno de origen criollo, o de españoles que han tenido una larga estancia en América, y que son repatriados a su país una vez finalizada la ocupación colonial española en Cuba, Puerto Rico y Filipinas. Véase en el cuadro 4, el incremento de pasajes de funcionarios civiles y familiares a fines del siglo XIX, sobre todo desde 1895 en adelante.

La importancia que adquiere la emigración oficial en el caso español, no se puede separar de la política colonialista desarrollada por los gobiernos del siglo XIX. En el contexto del colonialismo español del siglo XIX, se puede entender la importancia que tenía para el Estado la atención de las comunicaciones marítimas con sus posesiones de Ultramar, tanto en su faceta de correos marítimos, transportes oficiales, como en la conservación de los últimos vestigios del prestigio de potencia colonial que España había ido perdiendo a lo largo de la centuria. Aspecto que en ningún momento se desvinculó de los intereses materiales, de aquéllos empresarios que disfrutaban del privilegio de los mercados coloniales. Las palabras de Víctor Balaguer, ministro de Ultramar en 1886, encargado de presentar a las Cortes el contrato del Gobierno con la Trasatlántica para el transporte del correo, las tropas y funcionarios, no deja duda sobre la importancia que se le daba al asunto:

España tiene una deuda con su glorioso pasado, y otra no menos sagrada con su misión civilizadora, en el continente africano; así es con provecho propio debe cuidar de los cuantiosos intereses creados por nuestros inolvidables antecesores en la América española y Oceanía, a la vez que, sobre las sólidas bases de nuestra prosperidad comercial abrir nuevos y esplendorosos horizontes a generaciones futuras (17).

(17) Correspondencia sin clasificar. AHCT. 
El discurso del ministro continuaba numerando detalladamente las virtudes civilizadoras y el genio colonial de la «raza española", así como los beneficios que obtendría el gobierno y la «nación» mediante el contrato suscrito con la Compañía del Marqués de Comillas, relacionando directamente el fortalecimiento del potencial marítimo mercante y de guerra, con la conservación de la integridad territorial en Ultramar y la conquista de nuevos mercados.

Los gobiernos de la Restauración hacían de sus relaciones con la Trasatlántica una cuestión de Estado, e intentaban a través de ella recuperar el terreno perdido en el campo de la navegación atlántica, donde las compañías inglesas, francesas y alemanas -que también contaban con la importante protección de sus gobiernos - controlaban buena parte del tráfico con Ultramar. Pero los esfuerzos en este sentido fueron infructuosos, los intentos de la compañía por abrir nuevas rutas, y entrar a competir en la contratación de emigrantes europeos a través de convenios con estados americanos -México y Argentina-, y abriendo oficinas en Italia desde donde comenzaron a zarpar los buques que desde el Mediterráneo iban a la región del Río de la Plata, no permitieron consolidar una gestión económica independiente de sus contratas oficiales. Las subvenciones del Estado en las rutas antes enumeradas y sobre todo el transporte de militares en los períodos de confrontación bélica en las colonias, siguió siendo el factor clave.

El transporte de tropas y oficiales del ejército y la armada era una consecuencia directa de la situación colonial que mantenía España en Cuba, Puerto Rico y Filipinas. La desaparición de estos lazos en 1898 tuvo graves consecuencias para la Trasatlántica. La ausencia de transporte de militares y el escaso número de funcionarios civiles que exigía la diplomacia española obligó a la Compañía a buscar nuevos mercados e intentaron introducirse en el transporte de emigrantes italianos con unos resultados limitados y como último recurso, les quedaba la posibilidad de conseguir un incremento en las subvenciones a los vapores correo.

Un claro ejemplo de lo que representó la pérdida de las colonias para la Compañía Trasatlántica, lo encontramos en la lectura de la correspondencia de la empresa en los años inmeditamente posteriores al desastre colonial. En carta fechada en Manila el 18 de septiembre de 1899, S. Maristany que había estado muchos años vinculado a la empresa, respondía a las 
consultas de Joaquín Guerra, que permanecía en Cádiz, de la siguiente manera:

Mi criterio, Dn. Joaquín, es sumamente radical, porque entiendo que dadas las circunstancias, y plageando una frase de Silvela (que no ha sabido cumplir), entiendo que se debe ir en economías, hasta la crueldad, si se aspira a vivir.

Usted sabe que siempre llevamos vida de rico, y que a esa clase de vida en la Trasatlántica está viciado el personal todo. Pues bién, ahora hay que procurar vivir, no diré vida de pobre, pero si vida modesta con singular Administración.

No es viable el pensamiento del Sr. Presidente (dicho sea con perdón) de reorganizar los servicios sin consecuencia sensible para el personal. Punto es este naturalmente de dolor; pero dolor de corazón, no dolor de conciencia, y si se aspira a vivir hay que abordarle con decisión. La fuente de ingresos se ha mermado tan notablemente que no bastaría, no, la reorganización solo del material si no sumara a él un gran factor procedente de economías en el personal (18).

(18) Ibidem. 